\title{
Increasing and diversifying turnout in non-electoral participation - a field experiment
}

\author{
Annabelle S. Wittels
}

November 11, 2020

\begin{abstract}
Non-electoral participation initiatives are regarded as the gold standard for good governance - encouraging and sustaining democratic engagement. However, participation rates typically are low and disadvantaged groups under-represented. A large body of evidence shows that communication campaigns can increase participation in elections. However, the evidence base for non-electoral participation is scarce and in many aspects completely lacking. This study contributes to the literature by theorising and empirically testing whether such inequalities can be redressed. It uses a randomised field experiment with 29,008 households in a large city in the UK to test the effect of different direct mail messages on participation. It illustrates that rigorous testing of interventions is necessary to understand their impact across different democratic contexts: Contrary to what theory would predict for electoral contexts and paid-for work, all tested interventions significantly decrease participation in the governance initiative under study.
\end{abstract}




\section{Introduction}

Responsive institutions and an engaged public are widely considered the bedrock of healthy democracies (Dahl, 1989). Participatory governance, mechanisms to incorporate opinions and feedback from the general public into the policy-making process in a systematic manner, is considered as the most promising approach to promote such ideals in developing and developed democracies alike (Fung and Wright, 2001; Altschuler and Corrales, 2012; Pateman, 2012; Speer, 2012; Fishkin, 2018). Participatory governance however suffers from a participation problem: participation rates tend to be low overall and minorities and lower income groups remain under-represented (Arnstein, 1969; Bishop and Davis, 2002; Moro, 2005). Deliberative fora or participatory budgeting have the best chances of promoting democracyenhancing behaviours among the public and policy-makers. However, their time- and knowledge-intensive nature discourages participation of those who cannot afford or do not want to spend their scarce spare time on engaging with technical matters of policy Butler and Arceneaux, 2015; Peixoto et al., 2017). In order to meet the demand for more participatory governance (e.g. see the OECD's best practice reports on the topic, which shame countries that do not incorporate such mechanisms in their policy-making) but reduce their resource intensity, many central and local governments rely on largescale surveys, often sampled to be representative by electoral wards. Frustratingly perhaps, even those low-effort mechanisms suffer from poor par- 
ticipation rates, especially amongst the typically underrepresented groups (Lowndes et al., 2001b a; Yang and Callahan, 2007; Coleman et al., 2011; Christensen et al., 2020).

This begs the question whether governments can deploy strategies to increase and diversify participation rates. Ideally, this would be done in a manner that honours people's freedom to decline to participate and their anonymity. Nudges, small changes to how a policy is communicated or enacted without resorting to legislation, could be an attractive solution.

The main contributions of this study are two-fold: It contributes to the literature on democratic theory more broadly and specifically claims made about participatory governance by theorising scope conditions for incentivising and diversifying turnout for participatory governance initiatives. It then empirically tests whether inequalities can be redressed by different mobilisation strategies. In addition, the study extends the get-out-the-vote (GOTV) literature situated in political science into the field of non-electoral participation and governance. This experiment thus purposely connects theory and empiricism by testing whether predictions deriving from the field of political science extend into the context of public administration (Bertelli and Riccucci, 2020).

Using a randomised field experiment, it evaluates the effect of six different communication strategies aimed at promoting participation and diversifying participation in an annual, citizen consultation in a large, diverse city in the United Kingdom. 


\subsection{Non-electoral forms of participation and citizen consultations}

Most democratic countries have made public engagement exercises part of the routine of policy-making and planning (OECD, 2009). While there is a great variety of public engagement types, citizen consultations, which typically involve asking the public to comment on legal documents or complete surveys on the policy issue, are most commonly used in the OECD (Moro, 2005; OECD, 2009). Citizen consultations can be tokenistic power sharing arrangements (Arnstein, 1969) or lead to genuine co-creation of policy outputs (Bishop and Davis, 2002; Leighley and Oser, 2018), depending on the extent to which there is a commitment to consult before policy decisions are fixed and to use results in policy design and implementation.

The evidence base for citizen consultations and other non-electoral participation is scarce and in many aspects completely lacking. Studies of public participation are mainly situated in the fields of (urban) planning and public administration. The majority of work on this subject remains descriptive and sometimes borders the naively enthusiastic (Bishop and Davis, 2002; Catt and Murphy, 2003; Shipley and Utz, 2012; Kroll et al., 2017; Oh and Lim, 2017; Neshkova and Guo, 2018, for commentary). Studies that discuss barriers to public participation pervasively note the skepticism and cynicism of bureaucrats tasked with managing these processes and delivering policy recommendations based on their results. 
Representativeness or more precisely the lack thereof is core to this scepticism. Bureaucrats note that organised interests turn out at a higher rate than minorities and "average citziens" (Lowndes et al., 2001b; Bickerstaff and Walker, 2005; Buckwalter, 2014). Empirical work further suggests that the input that is provided from "average citizens" still comes from a narrow range of opinions and demographic backgrounds (Lowndes et al., 2001b; Shipley et al., 2004; Bickerstaff and Walker, 2005; Uyesugi and Shipley, 2005). Often citizens are simply not aware of the opportunity to participate. This is mainly due to a lack of resource mobilisation on behalf of governments (Yang and Callahan, 2007).

Yet, even when citizens are aware of opportunities, there is a lack of demand for participation. A (perceived) lack of time (Lowndes et al., 2001b; Yang and Callahan, 2007), prohibitive cost (Helling, 1998) and low internal and external political efficacy supress demand for participation (Lowndes et al., 2001b; ; Yang and Callahan, 2007; Coleman et al., 2011; Christensen et al., 2020). There has been little to no work published on how to increase and diversify participation.

A few exceptions exist: Butler and Arceneaux (2015) tested different forms of encouragement (mailed postcards) to serve on a local government committee in a field experiment. They find that offering social recognition has no significant effect and offering training targeted at increasing the internal political efficacy of participants backfired - it reduced participation.

Butler and Arceneaux (2015) theorise that the training treatment back- 
fired because it implied that the task at hand was difficult - it required training - and that it involved a substantial time commitment. In their view, recognition might not have had a positive effect on turnout as it signalled that serving on the committee was above and beyond one's civic duty.

However, with a lack of empirical tests of interventions targeted at increasing turnout in non-electoral public participation, it remains unclear whether the negative effects that Butler and Arceneaux (2015) observe are an artifact of their interventions or are a results of a mismatch between interventions and incentive structures at play. It is plausible that different incentive structures exist for non-electoral public participation compared to voting, they might require a different set of interventions to mobilise people.

An alternative explanation is provided by Butler and Hassell (2018). They theorise that any government communication that encourages non-electoral public participation will backfire because it signals to citizens that the government is already taking care of the issue. Citizens know the issue is already on the government's agenda and they leave to the discretion of their elected representatives what happens to it. Thus, behavioural messages might encourage free riding instead of increasing participation (Hensel et al., 2019).

However, there are some positive results. Peixoto et al. (2017) find that email encouragements to take part in an online participatory budgeting exercise significantly increase participation. In another field experiment, Hock et al. (2013) tested whether invitation phone calls can increase attendance of town hall (civic) meetings. While they found a positive effect of phone calls, 
they only increase participation among residents who are business owners thus, only for people who had an economic stake in the policy under discussion. Their intervention thus clearly only increased participation among a very specific subset of people. What is more, the studies by Peixoto et al. (2017) and Hock et al. (2013) both look at forms of non-electoral public participation which explicitly encourage deliberation, which citizen consultations do not.

Compared to other forms of participation, citizen consultations have lower salience and require greater effort to take part that voting. In addition, they suffer from a lack of readily available social norms relating to what should be done with their results and why participation should be regarded as socially desirable.

Citizen consultations might be more akin to volunteering and acts of charity, by which one gives up time and potentially money to contribute to a cause. Literature on contributions on public goods might therefore be best suited to inform what could be viable interventions to boost participation in citizen consultations.

\subsection{Evidence on increasing contributions from the pub- lic goods literature}

Non-electoral forms of participation differ from electoral forms in terms of having (i) less strong social norms attached to them; (ii) often involve con- 
siderably more burdensome actions than voting - i.e. they are harder, take more time or require more specialised knowledge; (iii) they are less "fun" than elections - for instance there is no media hype, no tribalism, no euphoric parties, no loser's tears; and in most countries they (iv) have a worse riskreward ratio compared to elections, as decisions about how input is handled are more opaque and through-put is not pledged like in election manifestos. This makes participating in non-electoral forms of public participation more like supporting - perhaps niche or highly localised - charitable causes.

Literature on voluntary acts and levels of effort suggests that the following interventions have the potential to improve participation rates: (i) lotteries are fun and can improve a poor risk-reward ratio by promising an extrinsic in addition to existing intrinsic rewards; (ii) symbolic rewards - i.e. nonmonetary rewards - also improve the action's risk-reward ratio and carry the potential of reinforcing positive social norms; (iii) improving external political efficacy such as through clarifying pathways of accountability and impact can improve the perceived risk-reward ratio, while improving internal political efficacy can decrease to what extent participation is experienced as burdensome; (iv) finally reducing anonymity of participation processes can render them more public and thereby encourage the development of stronger social norms. We will discuss each of them in more detail below. 


\subsubsection{Offering financial incentives}

Several studies from public economics find lotteries lead to larger contributions (Morgan and Sefton, 2000; Lange et al., 2007). This effect seems to be independent of risk preferences (Lange et al., 2007) and has also been demonstrated outside the laboratory, in field experiments (Landry et al., 2006). In the long-run, financial incentives can however be problematic. There is a fear that they might crowd-out intrinsic motivations, meaning that without the external incentives, people no longer want to contribute (e.g. Meier, 2007) Yet, most field experiments looking at taxation and donations find no such effects (Eckel et al., 2005; Dwenger et al., 2014) or only partial crowding-out Adena and Huck, 2017). In a more political context, John (2016) find that lotteries can increase electoral registration. There is thus suggestive evidence that lotteries could also increase participation in citizen consultations.

\subsubsection{Providing symbolic rewards}

A viable alternative to lotteries might be to use non-monetary rewards, or so-called symbolic rewards. Symbolic rewards span a wide range of gestures - from a simple thank-you to elaborate ranking systems and award ceremonies. Empirical tests of symbolic rewards for public participation are few. Panagopoulos (2011) tested the effect of thank-you messages included in di-

rect mail campaigns on electoral turnout in the US. He finds that messages of gratitude significantly increase turnout across three elections with different 
salience levels and taking place in different locations and at different times. Notably, the effects are fairly consistent across contexts and larger than those observed from direct mail campaigns which do not feature thank-you messages (Gerber and Green, 2000; John and Brannan, 2008; Fieldhouse et al., 2014).

Most other studies on the topic of symbolic rewards come from economics and management studies (Grant et al., 2007; Kosfeld and Neckermann, 2011; Bellé, 2015; Gallus, 2015; Bradler and Neckermann, 2016). For example, Bellé (2015) finds in a field experiment that nurses perform better (number of surgical kits assembled within a limited time) when they are promised a symbolic reward (an award for performance).

\subsubsection{Prompting beliefs of political efficacy}

In qualitative case studies of participation across the UK, Lowndes et al. (2001a) observed that many citizens felt participation in citizen consultations and similar public engagement exercises were futile. For many, government communication about public participation lacked goal clarity. Across studies, citizens also noted a lack of external efficacy - they felt that what they demanded would not be reflected in policy (Lowndes et al., 2001a). Political efficacy has been widely studied in political science and its sub-field political psychology (Finkel, 1985, for an overview). Goal clarity and efficacy are also identified as key drivers of motivation and task performance in studies deriving from the behavioural sciences (Kluger and DeNisi, 1996; Hysong, 
2009).

While it is difficult to affect internal political efficacy through improved government communications - one's political literacy, for instance - external political efficacy and goal clarity could be increased. Making it clear why people should participate in a citizen consultation might increase participation.

\subsubsection{Suspending anonymity}

Anonymity might be an obstacle to public participation in citizen consultations. Usually, citizen consultations are publicised by faceless entities such as ministries, government departments or local government authorities. In other words, requests do not come from a specific person. With the exception of town hall meetings and focus groups, responses tend to be submitted remotely, online or via mail. One can imagine that receiving a letter, Facebook advertisement or similar from "authority X" more likely elicits Kafkaesque sentiments than a strong urge to contribute.

Empirical findings support this intuition; people tend to be less cooperative and generous when they are anonymous and interact with unidentified persons than when they are known by name or face (Fox and Guyer, 1978; Bohnet and Frey, 1999; Andreoni and Petrie, 2004; Small and Lerner, 2008; Alpizar et al., 2008). For instance, when game partners are identified by name or photo before playing a variety of economic games, people cooperate (Fox and Guyer, 1978) and donate more Andreoni and Petrie, 2004; Small 
and Lerner, 2008). These effects are not confined to laboratory settings (e.g. Alpizar et al., 2008). Knowing who will handle one's responses might imbue citizens with more confidence and trust in the process. Further, removing anonymity would make it easier for citizens to hold specific persons to account when input is not handled as promised. Decreasing anonymity could hence promote participation.

\subsection{Hypotheses}

The number of treatment arms was based on power simulations conducted as part of the trial planning. The results are available in the pre-analysis plan registered at EGAP ${ }^{1}$ Households were block-randomised into one of seven arms: a control or one of six intervention arms (see next section for more details on the randomisation).

The control was based on the city's mailing used in the previous year, only with minor changes to colour scheme, date and website links. The consultation solicited responses only from a randomly selected sample of households, meaning that people who were not part of this random selection could not have known of the citizen consultations. This meant that there was no pure control (i.e. a group that received no mailing at all). The control is therefore the mailing that was based on that of previous years; it represents the status quo and can thus inform us on what would happen if

\footnotetext{
${ }^{1}$ The pre-analysis plan is available for download at the following URL (EGAP registration number: 20181219AB): http://egap.org/registration/20181219AB
} 
governments would change nothing about how they currently try to engage citizens. In the year previous to the study, when the status-quo message was used, the consultation attracted about 3,500 responses $(<1 \%$ of the resident population). Of these, $6 \%$ had a black and minority ethnic background (BME) while $13 \%$ of the city's population falls into this category. BME citizens were thus substantially under-represented in the consultation.

The treatment interventions were designed based on the reviewed literature, with the expectation that they would increase participation rates compared to the status quo (control) mailings.

All treatments comprised of changes to text and images of the control letter. The following interventions were chosen: (i) symbolic reward, (ii) anonymity reduction, (iii) financial incentive, (iv) political efficacy, (v) symbolic reward and anonymity reduction combined and (vi) a combination of symbolic reward, financial incentive and anonymity reduction, which - for simplicity - we will refer to as the "all behavioural" treatment from here on (see the online appendix for full materials).

The symbolic reward was designed to be a thank-you message and the promise to send a digital report on the survey outcomes, with a tailored message about the participant's neighbourhood and areas of interest. The tailored message was designed to be similar to certificates, a commonly used symbolic reward.

The report included statistics about health habits, loneliness, social activities and public service quality. This was framed as "learning about what 
one's neighbours think about [the city]". If the citizen participated, they received the report via email once the project had finished.

The anonymity-reducing intervention was an appeal from the mayor directly to the citizen, including a personal signature and picture.

The financial incentive condition consisted of a lottery that participants entered automatically when they submitted the consultation form. They could win a shopping voucher worth 200 British Pounds (about USD 260), which they could use in a wide range of local stores.

The political efficacy intervention aimed to increase external political efficacy. The intervention consisted of an infographic that specified what citizens' tax money was used for and how input from citizens influences the allocation of such funds. A reference was included in the text that highlighted that participation in the previous consultation had led to specific changes in how the city government's budget was allocated. Thereby, the political efficacy message emphasised that citizens' participation led to concrete changes.

The two last interventions (T5 and T6) - combinations of some of the other interventions - were created as it is commonly observed that treatment effects using only a single mechanism are weak. It is assumed that treatment effects are additive and combining the interventions leads to a larger effect than using them individually.

For all treatments, the key message was also printed on envelopes. All envelopes, including the control envelope had the city's logo and the logo of 
the citizen consultation campaign printed on it.

Based on the literature, we expected all treatments to lead to higher participation rates than the control. We expected some heterogeneity in the magnitude of the effects:

The symbolic reward treatment to the contrary might appeal more to already engaged citizens, who care about well-being statistics collected as part of the consultation. They are likely more educated and live in less deprived areas.

The anonymity treatment in general should increase participation for all. In the case of this experiment we however expected that would especially increase participation rates for citizens from high BME neighbourhoods. The mayor who is asking for submissions in the anonymity treatment is Black British Caribbean. The anonymity treatment might therefore also work as an identity appeal for black citizens.

The financial incentive treatment is expected to increase participation rates especially among lower income individuals as the prize offered signifies a larger marginal gain for low-income individuals than wealthier ones. The political efficacy treatment should have a larger marginal effect for people from lower socio-economic groups as they tend to have lower levels of internal and external efficacy. On the other hand, we might observe a threshold effect, by which a certain level of education and interest in government needs to be present enough to engage with the information to have a persuasive or motivating effect. 
The combined treatments should lead to higher rates of participation than other treatments if the effects are additive. However, a trade-off of more messaging is that there is more information to process. According to the cognitive load theory, presenting more information can lead to disengagement or poor processing - this is especially true for people from low socio-economic backgrounds (Sweller and Kalyuga, 2011). The last two treatments might therefore not be as well suited for diversifying participation as some of the other treatments.

\section{Experimental Design}

\subsection{Field context}

This field experiment took place in a large city in the UK, in fall and winter 2018. Similar to other large cities in the UK, it historically is a Labour Party stronghold. At the time of the field experiment, a minority ethnic Labour mayor had been in power.

The population size of the city is comparable to Miami, Florida or Tallinn, the capital of Estonia. Compared to the rest of the UK, the city has a relatively young population and is rapidly diversifying.

The public participation exercise that was central to this field experiment was a large-scale citizen consultation, which the city government repeats every year. The consultation centers around health and well-being issues but 
also covers themes such as satisfaction with local government services. The city bases several of its budgeting decisions on the results of this consultation. For instance, in previous years the city government adapted its allocations to serve problem areas and areas with poor indicators for health and wellbeing. Participating in the consultation involved completing survey, which covered perceptions and experiences with one's neighbourhood, housing, local services, diet, exercise, education and job prospects, and several personal details ${ }^{2}$

The survey could be completed by scanning a QR-code on the mail-out or typing the short website URL into a browser. If the consultation form was not submitted within 2-3 weeks from the mail-out date, the city government sent a paper survey with another reminder for completion to the household. In the reminder, households were encouraged to complete the online form but if they preferred, they could mail back the paper form without cost. All reminders featured the same treatment message as the initial letter and otherwise were identical for all experimental conditions.

\footnotetext{
${ }^{2}$ The consultation asked for a considerable time commitment. Reducing the time commitment necessary for completing a consultation is a worthwhile endeavour in and of itself. However, this study focused on communication mechanisms advertising and encouraging participation.
} 


\subsection{Random assignment and implementation}

The city government has a practice of using stratified random sampling to target a subset of their population for high impact citizen consultations. In this case, the city government sampled 29,008 households - a sample that was representative of population distributions across political wards. We then used the anonymised sample of households to block-randomise households into a control group and one of the six interventions. Random assignment was blocked by deprivation level of the neighbourhood, the percentage of BME residents in the neighbourhood and political ward, all at LSOA2-level, the smallest statistical unit surveyed by the Office of National Statistics (ONS) of the UK. IDs were constructed from the postcode plus the intervention link and the possible number of submissions per postcode plus intervention combination, i.e. there was a unique ID for each household. ANONYMISED Research Ethics Committee provided the ethics approval. The letters included a URL and QR code. The QR code could be scanned with a mobile phone and led citizens directly to the webpage containing the consultation form. Survey pages and content did not differ between interventions. The consultation survey was not searchable and could not be navigated onto from any other page of the city's government's webpages. The envelope of each treatment mailing included the key message printed on the outside, to increase the likelihood that households were exposed. Even if a household member did not open or read the letter, they likely caught the key message 
on the envelope when they found their mail at home.

\subsection{Outcomes and analysis strategy}

Participation is measured as completing and submitting the consultation form, online or via mail. This is coded as a binary variable (Y). We use OLS regression with fixed effects for blocks to estimate the Intention-to-Treat effect 3

\section{Results}

There were a total of 3,100 valid submissions to the citizen survey. An additional 773 submissions were made through non-randomised links. These submissions were set to zero $(\mathrm{Y}=0)$ for the main analysis, counting them as non-participation since it was not clear whether the letters or some other reason had led these households to submit a response. In a robustness check, we set the same submissions to $Y=1$ and count them. The conclusions do not change (Table 5).

For all households, data on the BME composition and deprivation level of their neighbourhood is available. There is no other information available on these households. As intended, the treatment groups do not differ in terms of

\footnotetext{
${ }^{3}$ Note that this approach is more conservative than that included in the pre-registered analysis plan. Further, based on some simulation tests conducted by (Blair et al., 2018), We will repeat these analyses computing differences-in-means computed by block and taking their weighted sum. P-values for these estimates will be estimated using randomisation inferences.
} 
the blocked variables: deprivation level, BME percentage and electoral ward of the household. Since all of these variables are recorded as categories, we use Chi-Square tests to check for significant differences in cell counts between treatment groups (see online materials for full results).

It appears that manipulation was effective for the vast majority of households. Since the consultation links were not publicly available, participants needed to see the letters, open them and type the included link into a web browser or scan the QR code to submit a response. Only nine letters were returned to the sender. Further, a multiple choice and free text question was included in the consultation form; it asked citizens to state where they had heard about the consultation. Of the 3,100 valid submissions 3,004 citizens stated that they had heard about the consultation via a government letter that they had received (97\% of submissions). Given the multitude of steps necessary to get to the website, it is thus very likely that households read either both or one of the treatment messages printed on the envelope or those included in the letter, which were the most prominent feature (see online supplementary appendix for intervention materials) $4_{4}^{4}$

\footnotetext{
${ }^{4}$ It is however not possible - as in many field experiments - to assess how households construed the messages included in the letters and which particular elements drove them to act as they did (Paluck and Shafir, 2017).
} 
Table 1: Intent-to-Treat (ITT) Effects on Participation (submission of a survey)

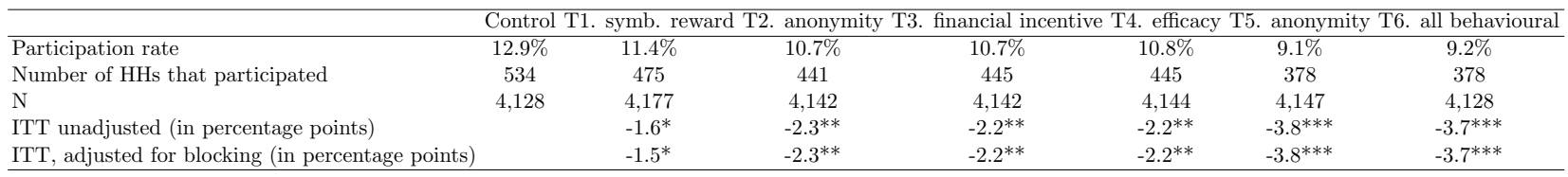

Table 2: Results of balance checks (post-treatment)

\begin{tabular}{|c|c|c|c|c|c|c|c|c|c|c|}
\hline & All & Control & T1 & $\mathrm{T} 2$ & T3 & T4 & T5 & T6 & $\mathrm{X} 2$ & $\mathrm{p}$-value \\
\hline Deprivation level & $19.7 \%$ & $20.6 \%$ & $20.1 \%$ & $19.5 \%$ & $19.7 \%$ & $19.8 \%$ & $19.8 \%$ & $19.8 \%$ & 2.01 & 0.918 \\
\hline BME \%age & $14.95 \%$ & $15.1 \%$ & $15.2 \%$ & $14.9 \%$ & $15.1 \%$ & $15.0 \%$ & $14.4 \%$ & $14.9 \%$ & 1.63 & 0.950 \\
\hline Ward & & & & & & & & & 183.80 & 0.756 \\
\hline
\end{tabular}

\subsection{Intention-to-Treat effect}

Model 1 in Table 3 illustrates the results without the addition of covariates.

Model 2 provides an estimate of the treatment effects with fixed effects for blocks, as specified above (also see Table 1). Model 3 estimates the interaction of treatments, deprivation levels and BME percentage of the targeted neighbourhoods.

We find that all treatments backfire - they significantly reduce participation rates compared to the control. The "all behavioural" treatment performs worst and the symbolic reward treatment performs the least worse, with other treatments falling in between.

We repeat these analyses using logistic regression models, which are better fit for binary outcomes (Table 4). The main conclusions do not change. The logit model suggests that the combined symbolic reward and anonymityreducing treatment might reduce participation in neighbourhoods with high 
deprivation levels. However, this difference is only significant at $\mathrm{p}<0.1$. Further after controlling for multiple comparisons, the effect would disappear. Therefore, it is unlikely that differences are substantive.

As Table 5 illustrates, we find the same pattern as in our main analyses. All treatments seemingly perform worse than the control.

Next, as pre-registered, we look at effects by sub-group: how effects vary between neighbourhoods with high versus low levels of deprivation and those with a low compared to a high percentage of black-and-minority ethnic (BME) residents. All treatments have the same directional effect. Compared to participation rates in the previous year, overall participation of households located BME neighbourhoods increased from $6 \%$ to $8 \%$. To compare participation rates for households targeted by the status-quo message (the same as in the previous year) and treatments in a manner that is adequately powered, we pool all treatment conditions and compare their effect to that of the control (see online appendices for the full set of regression tables).

We find that for neighbourhoods that have a high proportion of BME residents and those which have both high levels of deprivation and a high proportion of BME residents, treatments have no effect. Participation rates do not shift compared to the control.

For neighbourhoods that have high deprivation levels treatments reduce participation rates by an average of 2 percentage points, slightly less than the average effect across all neighbourhoods which is -3 percentage points. Neighbourhoods that have both low levels of deprivation and a small percent- 
age of BME residents - in other words, those that are relatively well-off and British white -, treatments on average also reduce participation rates by an average of 3 percentage points; just as for the full sample. These conclusions are robust to clustering errors at a lower level (the postcode level). 
Table 3: Main results: ITT on participation

\begin{tabular}{|c|c|c|c|}
\hline & \multicolumn{3}{|c|}{ Dependent variable: } \\
\hline & \multicolumn{3}{|c|}{ Participation } \\
\hline & no covars & $\mathrm{w} /$ covars & w/ covar. int. \\
\hline & (1) & (2) & (3) \\
\hline \multirow[t]{2}{*}{ Symbolic } & $-0.016^{*}$ & $-0.015^{*}$ & $-0.018^{*}$ \\
\hline & $(0.007)$ & $(0.007)$ & $(0.009)$ \\
\hline \multirow[t]{2}{*}{ Anonymity } & $-0.023^{* *}$ & $-0.023^{* *}$ & $-0.026^{* *}$ \\
\hline & $(0.007)$ & $(0.007)$ & $(0.009)$ \\
\hline \multirow[t]{2}{*}{ Financial incentive } & $-0.022^{* *}$ & $-0.022^{* *}$ & $-0.022^{*}$ \\
\hline & $(0.007)$ & $(0.007)$ & $(0.009)$ \\
\hline \multirow[t]{2}{*}{ Efficacy } & $-0.022^{* *}$ & $-0.022^{* *}$ & $-0.029^{* *}$ \\
\hline & $(0.007)$ & $(0.007)$ & $(0.009)$ \\
\hline \multirow{2}{*}{ Symbolic + Anonymity } & $-0.038^{* *}$ & $-0.038^{* *}$ & $-0.039^{* *}$ \\
\hline & $(0.007)$ & $(0.007)$ & $(0.008)$ \\
\hline \multirow[t]{2}{*}{ All behavioural } & $-0.037^{* *}$ & $-0.037^{* *}$ & $-0.040^{* *}$ \\
\hline & $(0.007)$ & $(0.007)$ & $(0.008)$ \\
\hline \multirow[t]{2}{*}{ High deprivation area } & & $-0.039^{* *}$ & $-0.039^{* *}$ \\
\hline & & $(0.004)$ & $(0.013)$ \\
\hline \multirow[t]{2}{*}{ High BME area } & & $-0.016^{* *}$ & $-0.032^{*}$ \\
\hline & & $(0.005)$ & $(0.014)$ \\
\hline \multirow{2}{*}{ Symbolic $\mathrm{x}$ High depriv. } & & & -0.004 \\
\hline & & & $(0.017)$ \\
\hline \multirow[t]{2}{*}{ Anonymity x High depriv. } & & & 0.003 \\
\hline & & & (0.017) \\
\hline \multirow[t]{2}{*}{ Fin. inc $\mathrm{x}$ High depriv. } & & & -0.002 \\
\hline & & & $(0.017)$ \\
\hline \multirow[t]{2}{*}{ Efficacy x High depriv. } & & & 0.011 \\
\hline & & & $(0.017)$ \\
\hline \multirow[t]{2}{*}{ Symbolic + Anonymity x High depriv. } & & & -0.015 \\
\hline & & & $(0.016)$ \\
\hline \multirow[t]{2}{*}{ All behavioural x High depriv. } & & & 0.008 \\
\hline & & & $(0.016)$ \\
\hline \multirow[t]{2}{*}{ Symbolic x High BME } & & & 0.025 \\
\hline & & & $(0.019)$ \\
\hline \multirow[t]{2}{*}{ Anonymity x High BME } & & & 0.018 \\
\hline & & & $(0.019)$ \\
\hline \multirow[t]{2}{*}{ Fin. inc $\mathrm{x}$ High BME } & & & 0.004 \\
\hline & & & $(0.017)$ \\
\hline \multirow[t]{2}{*}{ Efficacy x High BME } & & & 0.031 \\
\hline & & & $(0.019)$ \\
\hline \multirow[t]{2}{*}{ Symbolic + Anonymity x BME } & & & 0.025 \\
\hline & & & $(0.018)$ \\
\hline \multirow[t]{2}{*}{ All behavioural x BME } & & & 0.009 \\
\hline & & & $(0.018)$ \\
\hline \multirow[t]{2}{*}{ Constant } & $0.129^{* *}$ & $0.139^{* *}$ & $0.142^{* *}$ \\
\hline & $(0.005)$ & $(0.005)$ & $(0.006)$ \\
\hline Observations & 29,008 & 29,008 & 29,008 \\
\hline Note: & + & $<0.1 ;^{*} \mathrm{p}<$ & $05 ;{ }^{* *} \mathrm{p}<0.01$ \\
\hline
\end{tabular}


Table 4: Robustness checks using logit: ITT on participation

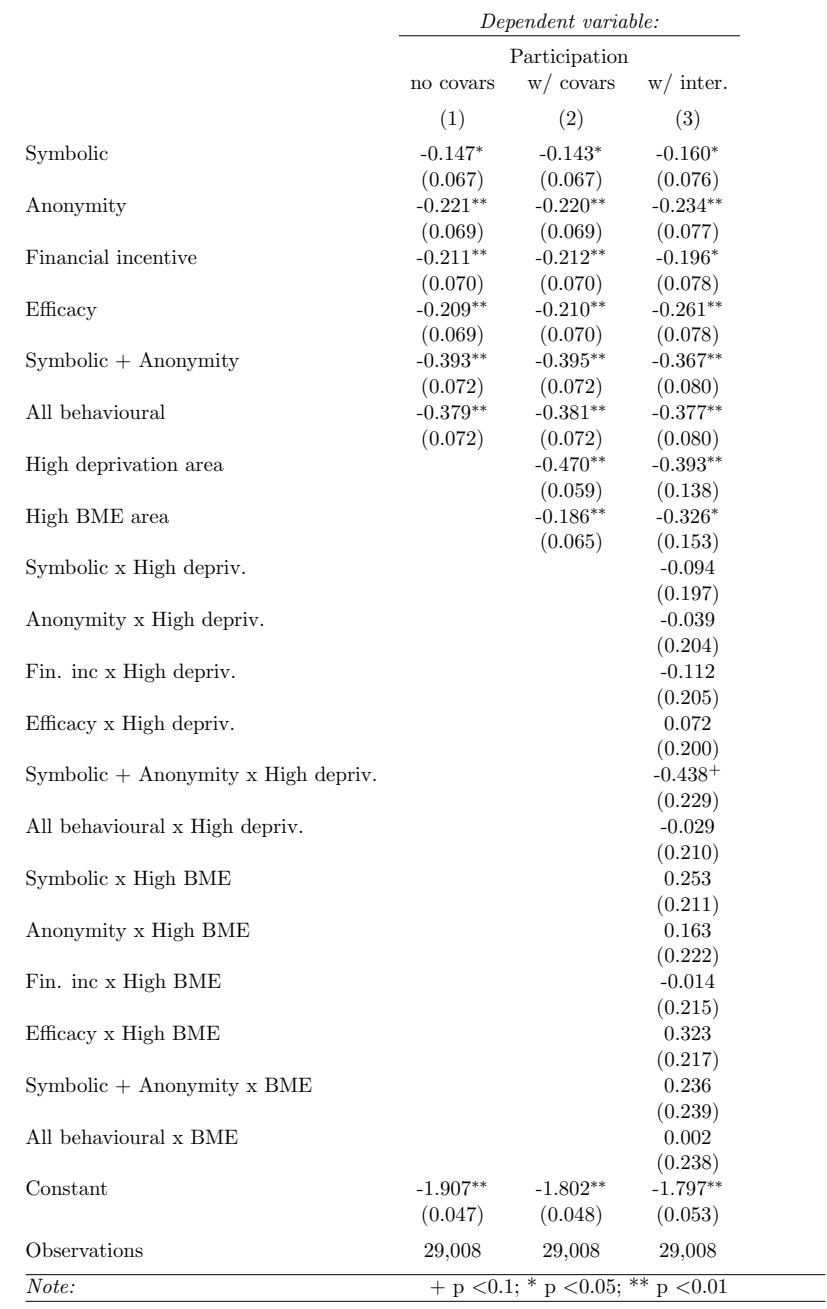


Table 5: Robustness check: ITT on participation with Y coded differently

\begin{tabular}{|c|c|c|c|}
\hline & \multicolumn{3}{|c|}{ Dependent variable: } \\
\hline & \multirow{3}{*}{$\begin{array}{c}\text { Participation } \\
\text { no covars } \\
\text { (1) }\end{array}$} & \multicolumn{2}{|c|}{ Participation } \\
\hline & & $\mathrm{w} /$ covars & $\mathrm{w} /$ inter. \\
\hline & & $(2)$ & $(3)$ \\
\hline \multirow[t]{2}{*}{ Symbolic } & $-0.016^{*}$ & $-0.015^{*}$ & $-0.018^{*}$ \\
\hline & $(0.007)$ & $(0.007)$ & $(0.009)$ \\
\hline \multirow[t]{2}{*}{ Anonymity } & $-0.023^{* *}$ & $-0.023^{* *}$ & $-0.026^{* *}$ \\
\hline & $(0.007)$ & $(0.007)$ & $(0.009)$ \\
\hline \multirow[t]{2}{*}{ Financial incentive } & $-0.022^{* *}$ & $-0.022^{* *}$ & $-0.022^{*}$ \\
\hline & $(0.007)$ & $(0.007)$ & $(0.009)$ \\
\hline \multirow{2}{*}{ Efficacy } & $-0.022^{* *}$ & $-0.022^{* *}$ & $-0.029^{* *}$ \\
\hline & $(0.007)$ & $(0.007)$ & $(0.009)$ \\
\hline \multirow{2}{*}{ Symbolic + Anonymity } & $-0.038^{* *}$ & $-0.038^{* *}$ & $-0.039^{* *}$ \\
\hline & $(0.007)$ & $(0.007)$ & $(0.008)$ \\
\hline \multirow[t]{2}{*}{ All behavioural } & $-0.037^{* *}$ & $-0.037^{* *}$ & $-0.040^{* *}$ \\
\hline & $(0.007)$ & $(0.007)$ & $(0.008)$ \\
\hline \multirow[t]{2}{*}{ High deprivation area } & & $-0.039^{* *}$ & $-0.039^{* *}$ \\
\hline & & $(0.004)$ & $(0.013)$ \\
\hline \multirow[t]{2}{*}{ High BME area } & & $-0.016^{* *}$ & $-0.032^{*}$ \\
\hline & & $(0.005)$ & $(0.014)$ \\
\hline \multirow[t]{2}{*}{ Symbolic $\mathrm{x}$ High depriv. } & & & -0.004 \\
\hline & & & $(0.017)$ \\
\hline \multirow[t]{2}{*}{ Anonymity $\mathrm{x}$ High depriv. } & & & 0.003 \\
\hline & & & $(0.017)$ \\
\hline \multirow[t]{2}{*}{ Fin. inc $\mathrm{x}$ High depriv. } & & & -0.002 \\
\hline & & & $(0.017)$ \\
\hline \multirow{2}{*}{ Efficacy $\mathrm{x}$ High depriv. } & & & 0.011 \\
\hline & & & $(0.017)$ \\
\hline \multirow[t]{2}{*}{ Symbolic + Anonymity $x$ High depriv. } & & & -0.015 \\
\hline & & & $(0.016)$ \\
\hline \multirow{2}{*}{ All behavioural x High depriv. } & & & 0.008 \\
\hline & & & $(0.016)$ \\
\hline \multirow[t]{2}{*}{ Symbolic x High BME } & & & 0.025 \\
\hline & & & $(0.019)$ \\
\hline \multirow[t]{2}{*}{ Anonymity $\mathrm{x}$ High BME } & & & 0.018 \\
\hline & & & $(0.019)$ \\
\hline \multirow[t]{2}{*}{ Fin. inc $x$ High BME } & & & 0.004 \\
\hline & & & $(0.017)$ \\
\hline \multirow[t]{2}{*}{ Efficacy x High BME } & & & 0.031 \\
\hline & & & $(0.019)$ \\
\hline \multirow{2}{*}{ Symbolic + Anonymity x BME } & & & 0.025 \\
\hline & & & $(0.018)$ \\
\hline \multirow[t]{2}{*}{ All behavioural x BME } & & & 0.009 \\
\hline & & & $(0.018)$ \\
\hline Constant & $0.129^{* *}$ & $0.139^{* *}$ & $0.142^{* *}$ \\
\hline & $(0.005)$ & $(0.005)$ & $(0.006)$ \\
\hline Observations & 29,008 & 29,008 & 29,008 \\
\hline Note: & $+\mathrm{p}<0$. & ${ }^{*} \mathrm{p}<0.05$ & $* \mathrm{p}<0.01$ \\
\hline
\end{tabular}


Figure 1: Intention-to-treat effect of treatments and significance compared to control

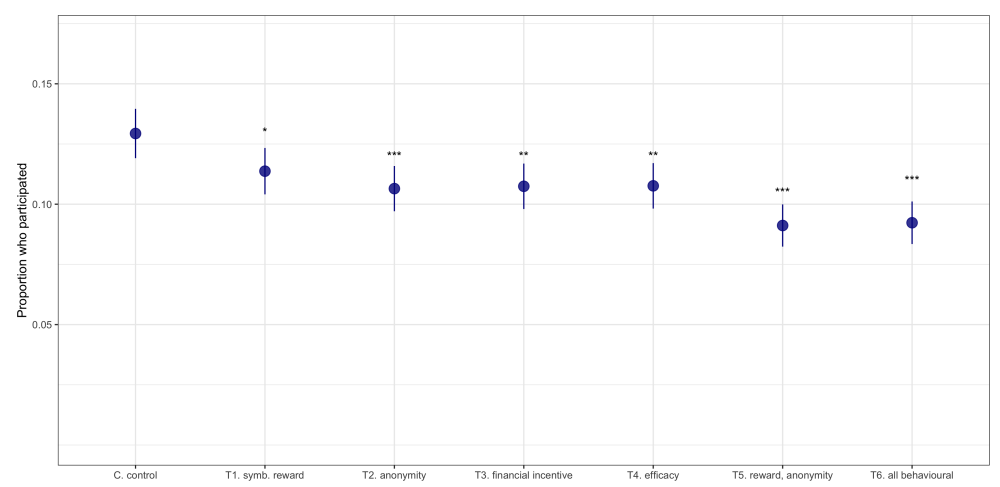

$\stackrel{\sqrt{ }}{\mathrm{N}}$

Figure 2: ITT by sub-group: neighbourhoods by BME percentage and deprivation level

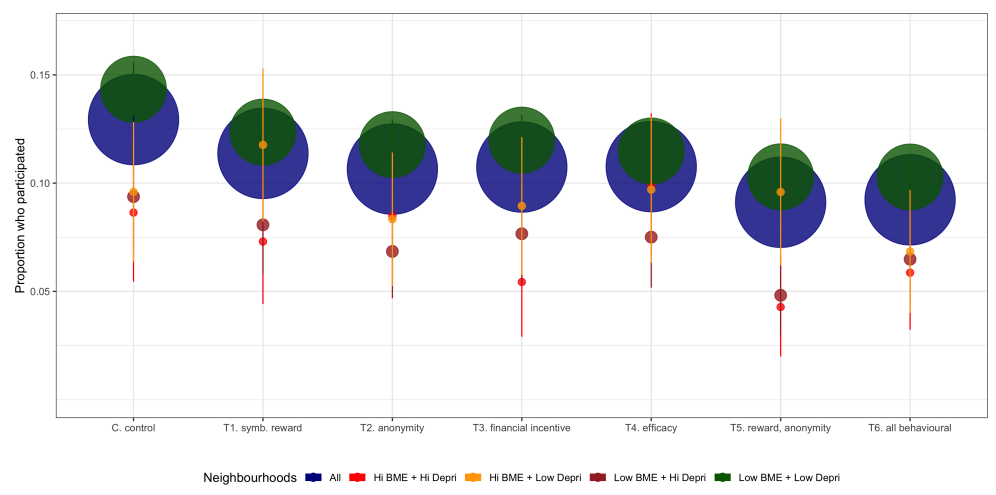




\section{Discussion}

Participatory governance initiatives hold the promise of supporting responsive institutions and encouraging the development of an engaged public. While most processes are often prohibitively resource intensive, large-scale surveys of citizens have become a convenient alternative for many governments across the developed and developing world (OECD, 2009, Speer, 2012). Citizen surveys offer little to no opportunity for communal deliberation but offer individual households to think and communicate about their preferences by filling out an online or a prepaid postal survey. Despite this apparent ease, citizen surveys typically suffer from low participation rates and systematically under-represent minority groups. An extensive body of literature on strategies to increase electoral participation exists (Gerber et al., 2003; Nickerson, 2007; Arceneaux and Nickerson, 2009; Nickerson, 2008, Panagopoulos, 2011). The literature suggest that smart communication interventions or so-called nudges, small changes to how choices are presented, could increase participation. However, the incentive framework and social context of non-electoral participation, in particular that which concerns government-initiated contact as opposed to grass root activism, differ substantially from electoral participation. It is therefore unlikely that the same strategies that have been demonstrated to increase turnout in elections will work in this context. Interventions targeted at increasing volunteering rates and engagement, deriving mainly from the fields of behavioural economics and psychology, provide a 
better match.

However, this study illustrates the importance of evaluating the effect of new interventions against existing policies and in a manner that allows to attribute causality. While the literature predicts that a use of such techniques should increase participation, the interventions markedly and consistently decrease participation. The more behavioural incentives are piled on the communication, the larger the reduction. This effect is heightened for constituencies that tend to have the most robust participation rates: more well-off, ethnic majority neighbourhoods. The interventions have similarly deleterious effects in higher deprivation neighbourhoods but do not affect those with a more diverse ethnic make-up. This pattern in outcomes points towards an erosion effect: existing intrinsic motivations are reduced or eradicated as alternative incentives are offered. Those citizens who were already committed to take part might have been put off by the additional incentives provided. There is evidence that external motivation can "crowd out" existing, internal drivers (Abadie et al., 2017). A crowding-out effect might be heightened when original motivations were heavily based on the assumption that participation is the norm, while the treatments suggested that this might not the case. Voting is associated with civic duty. If engaging in nonelectoral participation is similarly motivated and a message suggests that the action is not common among the general public, then the social norm might be degraded. This should affect contexts in which the norm is already weak even more so than contexts such as voting, where the norm is strong. In- 
deed, Robinson et al. (2019) finds that in a recently published study: rewards backfire for actions that are usually motivated by sense that one "ought" to do them.

An alternative explanation is that, compared to the control, treatments increased cognitive load (Sweller and Kalyuga, 2011). This was potentially because treatments used more text or visuals, which meant that the letter was perhaps harder and thus less appealing to process. Indeed, the "all behavioural" treatment performed worst, which would support such an explanation. Yet, there is no clear correlation between an increase in stimuli and performance of the letters. For instance, the political efficacy treatment used less text than the control and still performed worse.

Similar to what Butler and Arceneaux (2015) suggest, it is also possible that additional incentives suggest that the task at hand is more burdensome or difficult than people otherwise would assume. However, the instructions on how participate remained exactly the same across experimental conditions - they can therefore be excluded as potential drivers of differences in participation rates.

While some mechanism can be excluded, future trials should thus focus on disentangling (i) effects on intrinsic and extrinsic motivations, (ii) relations to existing social norms, (iii) the role of cognitive load, and (iv) heterogeneous effects on already committed and hard-to-reach populations. If governments could find ways to design citizen outreach that grow participation rates per se and also increases their representativeness, it would boost the prospects 
of public participation mechanisms to manifest as the democracy-supporting and -enhancing processes their proponents claim them to be.

That noted, it is imaginable that non-electoral public participation processes that do not offer the opportunity for deliberation will remain unpopular, regardless of incentives. If the public feels that citizen consultations are a mere tick-box or information collection exercise, without meaningful impact, changing government communication about them will not address a lack of broad-based participation. This trial could not effectively conclude whether an emphasis on efficacy and impact might shift attitudes and behaviour of minority citizens. This avenue is worth exploring further. However, it is likely that to incentivise people who are disengaged and have low levels of political knowledge, explanations of the connections between citizen input and policy output will need to be clarified further than what the infographic in the tested treatment letter could provide. As this study illustrates, rigorous systematic testing will be required for this.

Undoubtedly, change is not only desirable among the public. Increasing the representativeness of non-electoral participation processes could be a first step to improve their perceived legitimacy. In turn, this could encourage a virtuous cycle in which public officials also take such input more seriously and throughput of citizen feedback increases. The hope remains that if public participation processes can be strengthened, the health of democracy as a whole would strengthen. 


\section{References}

Abadie, A., S. Athey, G. W. Imbens, and J. Wooldridge (2017, November). When should you adjust standard errors for clustering? Working Paper 24003, National Bureau of Economic Research.

Adena, M. and S. Huck (2017). Matching donations without crowding out? Some theoretical considerations, a field, and a lab experiment. Journal of Public Economics 148, 32-42.

Alpizar, F., F. Carlsson, and O. Johansson-Stenman (2008). Anonymity, reciprocity, and conformity: Evidence from voluntary contributions to a national park in Costa Rica. Journal of Public Economics 92(5-6), 10471060.

Altschuler, D. and J. Corrales (2012). The Spillover Effects of Participatory Governance: Evidence From Community-Managed Schools in Honduras and Guatemala. Comparative Political Studies 45(5), 636-666.

Andreoni, J. and R. Petrie (2004). Public goods experiments without confidentiality: A glimpse into fund-raising. Journal of Public Economics 88(78), 1605-1623.

Arceneaux, K. and D. W. Nickerson (2009). Who is mobilized to vote? A re-analysis of 11 field experiments. American Journal of Political Science 53(1), 1-16. 
Arnstein, S. R. (1969). A Ladder Of Citizen Participation. Journal of the American Planning Association 35(4), 216-224.

Bellé, N. (2015). Performance-related pay and the crowding out of motivation in the public sector: A randomized field experiment. Public Administration Review 75(2), 230-241.

Bertelli, A. M. and N. M. Riccucci (2020). What is behavioral public administration good for? Public administration review.

Bickerstaff, K. and G. Walker (2005). Shared visions, unholy alliances: Power, governance and deliberative processes in local transport planning. Urban Studies 42(12), 2123-2144.

Bishop, P. and G. Davis (2002). Mapping Public Participation in Policy Choices. Australian Journal of Public Administration 61(1), 14-29.

Blair, G., J. Cooper, A. Coppock, and M. Humphreys (2018). The trouble with controlling for blocks. DeclareDesign Blog.

Bohnet, I. and B. S. Frey (1999). Social distance and other-regarding behavior in dictator games: Comment. American Economic Review 89(1), 335-339.

Bradler, C. and S. Neckermann (2016). The Magic of the Personal Touch: Field Experimental Evidence on Money and Appreciation as Gifts. Tinbergen Institute. 
Buckwalter, N. D. (2014). The potential for public empowerment through government-organized participation. Public Administration Review $74(5)$, $573-584$.

Butler, D. M. and K. Arceneaux (2015). How Not to Increase Participation in Local Government: Th e Advantages of Experiments When Testing Policy Interventions. Public Administration Review xx, 1-36.

Butler, D. M. and H. J. Hassell (2018). On the limits of officials' ability to change citizens' priorities: A field experiment in local politics. American Political Science Review 112(4), 860-873.

Catt, H. and M. Murphy (2003). What Voice for the People? Categorising Methods of Public Consultation. Australian Journal of Political Science 38(3), 407-421.

Christensen, J., L. Aarøe, M. Baekgaard, P. Herd, and D. P. Moynihan (2020). Human Capital and Administrative Burden: The Role of Cognitive Resources in Citizen-State Interactions. Public Administration Review $80(1), 127-136$.

Coleman, S., R. Gibson, and A. I. Schneeberger (2011). Democratic consultation and the e-citizen. Connecting Democracy: Online Consultation and the Flow of Political Communication, 173.

Dahl, R. A. (1989). Democracy and its critics. New Haven; London: Yale University Press. 
Dwenger, N., H. Kleven, I. Rasul, J. Rincke, N. Dwenger, H. Kleven, I. Rasul, and J. Rincke (2014). Extrinsic vs Intrinsic Motivations for Tax Compliance. Evidence from a Randomized Field Experiment in Germany. 8(3), 203-232.

Eckel, C. C., P. J. Grossman, and R. M. Johnston (2005). An experimental test of the crowding out hypothesis. Journal of Public Economics 89(8 SPEC. ISS.), 1543-1560.

Fieldhouse, E., D. Cutts, P. John, and P. Widdop (2014). When Context Matters: Assessing Geographical Heterogeneity of Get-Out-The-Vote Treatment Effects Using a Population Based Field Experiment. Political Behavior 36(1), 77-97.

Finkel, S. E. (1985). Reciprocal effects of participation and political efficacy: A panel analysis. American Journal of Political Science 29(4), 891-913.

Fishkin, J. S. (2018). Democracy when the people are thinking: Revitalizing our politics through public deliberation. Number November 2019.

Fox, J. and M. Guyer (1978). Public choice and cooperation in n-person prisoner's dilemma. The Journal of Conflict Resolution 22(3), 469-481.

Fung, A. and E. O. Wright (2001). Deepening Democracy: Innovations in Empowered Participatory Governance. Politics and Society 29(1), 5-41.

Gallus, J. (2015). Fostering public good contributions with symbolic awards: 
A large-scale natural field experiment at wikipedia. Management Science 63(12), 3999-4015.

Gerber, A. S. and D. P. Green (2000). The effects of canvassing, telephone calls, and direct mail on voter turnout: A field experiment. The American Political Science Review 94(3), 653-663.

Gerber, A. S., D. P. Green, and R. Shachar (2003). Voting May be HabitForming:Evidence from a Field Experiment. American Journal of Political Science 47(3), 540-550.

Grant, A. M., E. M. Campbell, G. Chen, K. Cottone, D. Lapedis, and K. Lee (2007). Impact and the art of motivation maintenance: The effects of contact with beneficiaries on persistence behavior. Organizational Behavior and Human Decision Processes 103(1), 53-67.

Helling, A. (1998). Collaborative visioning: Proceed with caution!: Results from evaluating atlanta's vision 2020 project. Journal of the American Planning Association 64(3), 335-349.

Hensel, L., J. Hermle, A. Rink, and C. Roth (2019). Political Activists as Free-Riders: Evidence from a Natural Field Experiment. BRIQ Institute Working Paper.

Hock, S., S. Anderson, and M. Potoski (2013). Invitation Phone Calls Increase Attendance at Civic Meetings: Evidence from a Field Experiment. Public Administration Review 73(2), 221-228. 
Hysong, S. J. (2009). Meta-Analysis: Audit \& Feedback Features Impact Effectiveness on Care Quality. Med Care 47(3), 356-363.

John, P. (2016). Finding exits and voices: Albert Hirschman's contribution to the study of public services. International Public Management Journal $0(0), 1-18$.

John, P. and T. Brannan (2008). How Different Are Telephoning and Canvassing? Results from a 'Get Out the Vote' Field Experiment in the British 2005 General Election. British Journal of Political Science 38(3), 565-574.

Kluger, A. N. and A. DeNisi (1996). The effects of feedback interventions on performance: A historical review, a meta-analysis, and a preliminary feedback intervention theory. Psychological Bulletin 119(2), 254-284.

Kosfeld, M. and S. Neckermann (2011). Getting more work for nothing? Symbolic awards and worker performance. American Economic Journal: Microeconomics 3(3), 86-99.

Kroll, A., M. I. Neshkova, and S. K. Pandey (2017). Spillover Effects From Customer to Citizen Orientation. Administration \&6 Society, 1227-1253.

Landry, C., A. Lange, J. List, M. Price, and N. Rupp (2006). Toward an understanding of the economics of charity: Evidence from a field experiment. The Quarterly Journal of Economics 121(2), 747-782.

Lange, A., J. A. List, and M. K. Price (2007). Using lotteries to finance 
public goods: Theory and experimental evidence. International Economic Review 48(3), 901-927.

Leighley, J. E. and J. Oser (2018). Representation in an Era of Political and Economic Inequality: How and When Citizen Engagement Matters. Perspectives on Politics 16(2), 328-344.

Lowndes, V., L. Pratchett, and G. Stoker (2001a). Trends In Public Participation: Part 1 - Local Government Perspectives. Public Administration 79(1), 205-222.

Lowndes, V., L. Pratchett, and G. Stoker (2001b). Trends in public participation: Part 2 - Citizens' perspectives. Public Administration 79(2), 445-455.

Meier, S. (2007). Do subsidies increase charitable giving in the long run? matching donations in a field experiment. Journal of the European Economic Association 5(6), 1203-1222.

Morgan, J. and M. Sefton (2000). Funding Public Goods with Lotteries: Experimental Evidence. Review of Economic Studies 67, 785-810.

Moro, G. (2005). Citizens' evaluation of public participation. Technical report, OECD.

Neshkova, M. I. and H. D. Guo (2018). Policy Target Populations and Public Participation in Agency Decision Making. International Public Management Journal 21(2), 297-325. 
Nickerson, D. W. (2007). Does Email Boost Turnout? Quarterly Journal of Political Science 2(4), 369-379.

Nickerson, D. W. (2008). Is voting contagious? Evidence from two field experiments. American Political Science Review 102(1), 49-57.

OECD (2009). Focus on Citizens - Public engagement for Better Policy and Services. Technical report.

Oh, Y. and S. Lim (2017). Connecting a missing link between participation in administration and political participation: the mediating role of political efficacy. International Review of Administrative Sciences 83(4), 694-716.

Paluck, E. and E. Shafir (2017). Chapter 6 - the psychology of construal in the design of field experiments. In A. V. Banerjee and E. Duflo (Eds.), Handbook of Field Experiments, Volume 1 of Handbook of Economic Field Experiments, pp. 245 - 268. North-Holland.

Panagopoulos, C. (2011). Thank you for voting: Gratitude expression and voter mobilization. Journal of Politics 73(3), 707-717.

Pateman, C. (2012). Participatory democracy revisited. Perspectives on Politics 10(1), 7-19.

Peixoto, T., F. M. Sjoberg, and J. Mellon (2017). A Get-Out-the-Vote Experiment on the World's Largest Participatory Budgeting Vote in Brazil. British Journal of Political Science, 1-9. 
Robinson, C. D., J. Gallus, M. G. Lee, and T. Rogers (2019). The demotivating effect (and unintended message) of awards. Organizational Behavior and Human Decision Processes.

Shipley, R., R. Feick, B. Hall, and R. Earley (2004). Evaluating municipal visioning. Planning Practice and Research 19(2), 195-210.

Shipley, R. and S. Utz (2012). Making it Count: A Review of the Value and Techniques for Public Consultation. Journal of Planning Literature 27(1), $22-42$.

Small, D. A. and J. S. Lerner (2008). Emotional policy: Personal sadness and anger shape judgments about a welfare case. Political Psychology 29(2), 149-168.

Speer, J. (2012). Participatory Governance Reform: A Good Strategy for Increasing Government Responsiveness and Improving Public Services? World Development 40(12), 2379-2398.

Sweller, John, A. P. and S. Kalyuga (2011). Cognitive Load Theory (1 ed.). Explorations in the Learning Sciences, Instructional Systems and Performance Technologies.

Uyesugi, J. L. and R. Shipley (2005). Visioning diversity: Planning Vancouver's multicultural communities. International Planning Studies 10(3-4), 305-322. 
Yang, K. and K. Callahan (2007). Citizen involvement efforts and bureaucratic responsiveness: Participatory values, stakeholder pressures, and administrative practicality. Public Administration Review 67(2), 249-264. 